\title{
Turbulent Combustion Modelling and Experiments: Recent Trends and Developments
}

\section{A. Giusti ${ }^{1,2} \cdot$ E. Mastorakos ${ }^{1}$ (D)}

Received: 26 February 2019 / Accepted: 4 September 2019 / Published online: 14 November 2019

(c) The Author(s) 2019

\begin{abstract}
The development of better laser-based experimental methods and the fast rise in computer power has created an unprecedented shift in turbulent combustion research. The range of species and quantities measured and the advent of $\mathrm{kHz}-\mathrm{level}$ planar diagnostics are now providing great insights in important phenomena and applications such as local and global extinction, pollutants, and spray combustion that were hitherto unavailable. In simulations, the shift to LES allows better representation of the turbulent flow in complex geometries, but despite the fact that the grid size is smaller than in RANS, the push towards realistic conditions and the need to include more detailed chemistry that includes very fast species and thin reaction zones emphasize the necessity of a sub-grid turbulent combustion model. The paper discusses examples from current research with experiments and modelling that focus on flame transients (self-excited oscillations, local extinction), sprays, soot emissions, and on practical applications. These demonstrate how current models are being validated by experimental data and the concerted efforts the community is taking to promote the modelling tools to industry. In addition, the various coordinated International Workshops on non-premixed, premixed, and spray flames, and on soot are discussed and some of their target flames are explored. These comprise flames that are relatively simple to describe from a fluid mechanics perspective but contain difficult-to-model combustion problems such as extinction, pollutants and multi-mode reaction zones. Recently, swirl spray flames, which are more representative of industrial devices, have been added to the target flames. Typically, good agreement is found with LES and some combustion models such as the progress variable - mixture fraction flamelet model, the Conditional Moment Closure, and the Transported PDF method, but predicting soot emissions and the condition of complete extinction in complex geometries is still elusive.
\end{abstract}

Keywords Turbulent combustion · Spray combustion · Large eddy simulation · Extinction · Laser diagnostics

E. Mastorakos

em257@eng.cam.ac.uk

Extended author information available on the last page of the article. 


\section{Introduction}

\subsection{Why study turbulent combustion?}

Turbulent combustion is the phenomenon at the heart of modern propulsion and energy and, even in a future low-carbon energy system, it is likely that there will be significant use of fuels for aviation, shipping, and manufacturing processes. Considering the aviation sector, for example, despite the push for more electrification and integration with the aircraft as the most promising strategies to further reduce emissions and fuel consumption [1, 2], the technology is still far from allowing for a fully electrical engine. The power density of the batteries, the weight of the cables as well as safety-related issues are some of the limiting factors for the full electrification of aviation engines. Therefore, even looking at the medium and long term, it is expected that combustion will still be part of the propulsion system of airplanes, either by generating directly the thrust or by providing the power (full or part of it in case batteries are used) for distributed electrical engines [2-7]. At the same time, explosion and fire risks will always necessitate knowledge of the underlying fundamentals of fluid flow, heat transfer, thermodynamics, and chemical kinetics. Turbulence is still an unclosed problem in fluid mechanics, while the kinetics of real fuels (fossil-based or biomass-derived) are still under development. It is clear, therefore, that turbulent combustion is still a practically very important problem.

In addition, turbulent combustion remains elusive from the perspective of comprehensive theory. To quote from R.W. Bilger [8],"With some 100,000 years of development, [combustion] might be expected to be a mature technology. In fact, it is the least developed technology of modern engineering systems. Engineering systems with mature technology have computer models that are routinely used in analysis and can be used in the optimization of the geometry and operating conditions of new designs. Thus the wings of new models of jet aircraft have subtle geometry contours that greatly increase their efficiency. The same can be said for the new generation of fans in turbo-fan engines. Computer modeling of combustors is still at a fledgling stage and is only used peripherally in the development of new combustors. Combustor development is still largely by cut-and-try testing in experimental rigs and in prototype and in-service engines and power plants". This was written in 2011, and perhaps takes a somewhat conservative perspective on the use of Computational Fluid Dynamics (CFD) for combustor design. Industry nowadays routinely do use CFD, but only for checking ideas, screening designs, and developing insights. The truth remains that the predictions made by combustion CFD are not quantitatively trustworthy yet, especially when it comes to pollutants and stability limits. This is partly because turbulent combustion modelling remains an important source of uncertainty to the overall simulation - we could add spray and kinetics as the other major areas where improvements are needed. This paper discusses the current state of turbulent combustion modelling with a focus on realistic devices and "difficult" flame problems such as flame extinction and pollutant emissions that push the capabilities of the models to their limit.

This paper is by no means an exhaustive review of current trends or of the literature in experimental, theoretical, and modelling research in turbulent combustion. It contains only a selection of material from the authors' experience, with the aim to present to the reader a personal view of the key areas of current activity and the limits of combustion CFD today. It is focused on gas turbine related flames (again, due to the authors' own activities in this area), although many of the comments made translate also to other applications such as spark ignition and diesel engines. The paper is mostly aimed at a starting $\mathrm{PhD}$ student who wishes to consult some entries to the vast literature on turbulent combustion. 


\subsection{A brief historical note}

Models for turbulent combustion have evolved over the years. The first theoretical ideas focused on how turbulence affects the mean flame shape and location. For instance, for premixed flames Damköhler's [9] relatively crude, but insightful, picture of turbulent flame speed is still being discussed, while for non-premixed flames the concept of "unmixedness" was diagnosed as early as 1948 [10-12]. We could argue that, perhaps, the first important steps in turbulent combustion modelling in the context of CFD were made in the 1970s, with the development of mixture fraction ideas for non-premixed combustion (see Ref. [13] for comments on the historical development of these and a first theoretical result that reaction rate can be related to the mixture fraction and its dissipation rate) and the Eddy-BreakUp model of Spalding [14], further developed by Magnussen [15]. Early combustion CFD attempts tried to establish global quantities like flame length and mean temperature (and, after insightful thinking and some tuning, even extinction $[16,17])$. Although we can now say that for many flames we can capture basic quantities with acceptable accuracy, the predictions remain inaccurate for some applications that bring the flame technology "to the limit", as in very lean, stratified, or pre-vapourised spray combustion. These examples and pollutant generation (especially $\mathrm{NO}$, soot, and $\mathrm{CO}$ close to walls) are manifestations of finite-rate kinetics, meaning situations where the chemistry cannot be considered as infinitely fast relative to the turbulent timescales, which is perhaps easier to analyse theoretically. The fact that the chemistry and the convection and diffusion processes in the turbulent flow compete in terms of timescales brings about a whole new complexity that needs to be addressed. Hence, new generation of models had to be developed for prediction of pollutant concentrations and even reaction zone length and position in case the chemistry is relatively slow or even very slow relative to the turbulent mixing. Such models include the flamelet approach [18-20], transported PDF [21, 22] (in both Lagrangian [23, 24] and Eulerian [25] sense), the Thickened Flame Model [26], the Conditional Moment Closure (CMC) [27-29] the Multiple Mapping Conditioning (MMC) [30, 31], and well-stirred reactor based models, sometimes called the "Eddy Dissipation Concept" (see Ref. [32] for a recent realisation of this model and some references).

We could argue that such efforts begun in the 1980s and are still ongoing. There has been a shift from tabulation-based approaches, where laminar flames are pre-calculated and used to produce relations between species mass fractions and reaction rates, to models where the convection/diffusion and chemistry for many reacting scalars are solved together in the simulation of the turbulent reacting flow, as in many of the above-mentioned models. The latter are more general as they do not make any assumptions on the flame structure. However, even now, after 50 years of intense turbulent combustion research, we are not in a position to predict from first principles in a CFD calculation the NO or soot emitted from a gas turbine or diesel engine, and we still cannot predict the operational limits of the flame (e.g. the full blow-off curve) in realistic devices.

Together with the models, experiments that focus on specific turbulent combustion phenomena emerged in the 1980s and are still being developed [8,33]. We could categorise the experimental activity in turbulent combustion research in two broad and often overlapping categories. First, the development of ever more accurate diagnostics, which aim to deduce hitherto inaccessible quantities like short-lived radical concentrations, multi-dimensional local reaction zone structures, and pollutants. Second, the exploration of more complex flames and at more representative conditions, so that the collection of data is done at flames 
and pressures closer to real applications. By "complex" we also mean more difficult phenomena, such as sprays [34], ignition [35, 36], extinction [37], and thermoacoustics [26]; see the cited references for an entry to the corresponding literature.

Despite the claims of some, there is currently no single validated model that can deal with all aspects of a practical turbulent flame, and no single experiment that covers all combustion physics. The authors are not aware of evidence that the available advanced turbulent combustion models in Large-Eddy Simulation (LES), probably the only combination with good chances of predicting accurately tough combustion problems, have been validated across the full range of phenomena that flames may experience in practice (for example, for emissions, extinction, high pressures, two-phase interactions, radiation). Therefore, significant scientific collaboration among modellers and experimentalists has emerged as crucial to the advancement of the field. Ground-breaking in this respect was the International Turbulent Non-premixed Flame Workshop [38], which was pioneered by a group of developers of turbulent combustion models and laser-diagnostic techniques. The idea was this: establish a flame that is simple from the perspective of fluid mechanics (and so the underlying aerodynamics will be relatively easy to predict with CFD), but bring it to the limit in terms of combustion science (in this case, bring the flame to extinction). Then, deploy on this flame more and more refined experimental techniques and models, and focus on how the turbulent combustion model behaves for such flames that have significant finite-rate kinetic effects. The success of this effort has been phenomenal and has served as the role model for other such focused activities, for instance the Turbulent Premixed Flame workshop [39], the Turbulent Combustion of Sprays workshop [40], the International Sooting Flame workshop [41], and the Engine Combustion Network [42], all of which focus on only a few combustion aspects and try to coordinate experiments and modelling so the models are fairly and extensively validated and compared. The hope is that subsequent jumping to combustion CFD in real applications will at least include models with correct validation of the basic turbulent combustion physics and chemistry.

\subsection{Objectives of this review}

This paper reviews the recent progress in modelling finite-rate kinetic effects in turbulent combustion, using extinction and pollutant generation as the prominent examples, and discusses how the above International Workshops have made a huge contribution to our understanding in this area and have precipitated more accurate models. In the next sections, some recent trends in experimental diagnostics and numerical modeling are presented. Examples from the authors' own research are also discussed to demonstrate the commonly-used validation procedures.

\section{Current Experimental and Modelling Challenges and Trends}

This Section is divided into four sub-sections. In the first two, we review respectively some recent trends in experimental techniques and models, starting from some recent reviews onwards and giving only a limited number of references, in the hope that what we give here is enough entry to the vast literature. We continue with a description of the coordinated focused international collaborations and we then present some examples of recent work with LES from our own lab, with the aim to demonstrate the nature of comparison that is currently taking place when the focus is on finite-rate kinetic effects. 


\subsection{Experimental diagnostics}

In early combustion research, optical methods based on emission were key to understanding the underlying chemistry [43]. Mirco-probes were also used to extract species from the flame so as to measure species concentrations, an activity that has helped develop kinetic models for combustion. For turbulent flames, sampling probes and thermocouples have provided very useful insights and time-averaged data for model validation [44, 45], but the limited spatial resolution, reaction quenching uncertainties, disturbance to the flame, corrections needed, and the fact that higher-order statistics (e.g. root-mean-square, PDFs) were often not available were factors that pushed towards the development of non-intrusive temporally-resolved diagnostics, mostly based on lasers. Excellent reviews of the basics and applications of laser diagnostics in combustion are available [46-49].

Single-point techniques provide a wealth of information at one point and time in the flow, and the emphasis is on capturing with sufficient accuracy the multi-scalar character of the flame. Hence, a combination of Raman and Rayleigh scattering has proved adequate for capturing many of the major species of interest (see, for example, Refs. [47, 50, 51] for a review and some recent developments), which allows validation of sophisticated models that solve for many reacting scalars together. Our understanding of the structure of non-premixed and of sooting flames has benefited enormously from such techniques.

Planar techniques, on the other hand, aim to capture a single scalar (or perhaps a few scalars simultaneously) in two dimensions and possibly in high enough repetition rate so the flame's spatial structure and its time evolution can be captured. Until about 2010, most planar spectroscopic systems were not fast enough to follow the fastest motions of the turbulence. However, the development of $\mathrm{kHz}-\mathrm{level}$ powerful lasers and intensified CMOS cameras have provided an unprecedented wealth of information - and size of data to be analysed and stored by the research group! Therefore, at present, many combustion labs have 10-50 kHz-speed cameras for $\mathrm{OH}^{*}$ and $\mathrm{CH}^{*}$ chemiluminescence and Planar Laser-Induced Fluorescence (PLIF) imaging of flames. Chemiluminescence helps locate the reaction zone and perhaps even understand quantitative trends of the heat release rate [52-54], which is of particular usefulness in thermoacoustics research. In such experiments, the time-resolved heat release rate (even if it is collected through a line-of-sight measurement) is particularly useful for understanding trends with frequency and amplitude of oscillation. However, chemiluminescence from chemical reactions in a flame is not always proportional to heat release; local strain and local equivalence ratio fluctuations affect the emission magnitude and hence the interpretation of the measurement is not evident. Nevertheless, chemiluminescence (usually of the excited $\mathrm{CH}^{*}$ or $\mathrm{OH}^{*}$ radicals) has proven to be very useful for understanding bulk flame motions and reaction zone location. Examples of careful use of $\mathrm{OH}^{*}$ and $\mathrm{CH}^{*}$ for inferring overall features of the combustion system are given in the thermoacoustics literature (e.g. [55-58]).

Similar cameras are used in conjunction with PLIF to image (but, most often, not measure quantitatively) species such as $\mathrm{CO}, \mathrm{OH}, \mathrm{CH}$, and $\mathrm{CH}_{2} \mathrm{O}[59,60]$. The greatest value of these fast two-dimensional techniques is the simultaneous visualisation of the reaction and important combustion scalars at many locations of the flow, which allows for insights (sometimes even quantitative) to be extracted on local and global extinction, and the presence of intermediate combustion products through the extinction process [60]. The example of flame extinction will be discussed in greater detail later when we compare Large-Eddy Simulations used for finite-rate kinetic effects against local flame extinction inferred from fast OH-PLIF, which has allowed very thorough validation of the sub-grid turbulent combustion model. 
Recent developments in PLIF include the imaging of NO [61], soot precursors like Poly-cyclic Aromatic Hydrocarbons (PAH) [62], H atom [63] and HCO [64]. The technical difficulties, resolution issues, lasers and cameras needed are discussed in the original papers. The user should be careful with the details of the laser, optics and camera system; small differences can affect signal quality considerably. The image processing (background reduction, laser sheet power non-uniformities, absorption of the laser or the fluorescent emission itself, non-linearities etc.) must also be carefully addressed for each PLIF system.

In addition to planar diagnostics, where often the focus is on capturing large sections of the reaction zone in order to see its continuity or shape, further improvements in the accuracy of point measurements have also been made recently, so that now the scalar dissipation rate, a most important quantity for either premixed and non-premixed flames, can be measured reasonably accurately. A good example of such an effort with a new multi-stream jet flame with compositional inhomogeneities is described in Ref. [65] where the details of the system and useful references to previous work on measuring gradients in reacting flows are given.

One of the most difficult quantities to measure in turbulent combustion is one of the most basic: the temperature. With intrusive probes (e.g. thermocouples) the time-averaged value is relatively accurately measured (with suitable corrections due to radiation losses and in the absence of catalytic effects on the wire). However, instantaneous values cannot be measured due to the finite response of the wire to the surrounding temperature fluctuations. Hence, laser-based systems are needed. Coherent Stokes Anti-Raman Spectroscopy (CARS) gives good accuracy with reasonable spatial resolution for some flames. Some new developments include the point measurement of temperature in sprays [66-69], a very novel and useful application of CARS with great potential for realistic combustors. In terms of planar techniques, two-wavelength PLIF systems have resulted in estimates of temperature for a range of flames (see, for instance, Ref. [70] and references therein), although care is needed in the interpretation of the results in turbulent flows because such systems do not really include any measurement from fluid particles with low temperatures hence biasing the statistics towards high values. This should be considered when doing comparison with simulations.

Apart from time-averaged or higher-order quantities, the availability of fast-response planar imaging has allowed the quantification of transients. For example, in some thermoacoustics problems the flame's response spectrum may have multiple peaks and these peaks may not be sharp, indicating non-linear response to the (often monochromatic) pressure and inlet flow oscillations [71]. Such information is used in low-order models of thermoacoustics and is also needed for validating LES for such problems. Various sophisticated data processing techniques have also been used, such as Proper Orthogonal Decomposition and Dynamic Mode Decomposition (e.g. [72-76]), but the physical insights extracted from such analyses are not always commensurate with the effort taken to develop them. At present, the main procedure of using the new capabilities offered by the fast diagnostics is through establishing well-converged averages, spatial structural quantities (such as two-point correlations), and spectral behaviour. These have already opened up huge opportunities for LES validation and further understanding of the behaviour of flames in complex combustors (e.g. [77-79]).

\subsection{Turbulent combustion models}

Systems of practical interest are usually characterised by complex configurations where both the fluid dynamics and the physics associated to the combustion process are challenging to predict. Several modelling approaches have been proposed so far and, as in every field 
that requires modelling, the choice of the best model depends on the specific application, boundary conditions and objective of the simulation.

Stable flames in simple configurations have been successfully simulated also with timeaveraged approaches and relatively simple combustion models. However, if the focus shifts to specific phenomena and transient effects, it becomes necessary to increase the complexity of the model. With the increase of the computational capability and power, LES has become more and more popular. It has been partly introduced also in the industrial design process, at least for the occasional detailed investigation of a few selected configurations. LES is not just more accurate compared to time-averaged approaches, but the unsteady solution of the flow field is often necessary to predict some flames of practical interest. This is due to the presence of a range of phenomena that are inherently unsteady, such as the vortex breakdown $[74,80]$ and the precessing vortex core [81] produced by swirling flows, typically used to stabilise the flame. Furthermore, unsteady approaches allow for a better representation of the mixing field that is of fundamental importance for a reliable prediction of pollutants. In addition, the quantification of the transient behaviour of flames is becoming more and more important in the definition of the operability of an engine. Therefore, reliable methods for unsteady flows are necessary.

As discussed in the previous sections, real combustors often operate in conditions characterised by a highly unsteady behaviour of the flame, where finite-rate chemistry effects may be relevant. At adverse conditions, the flame may exhibit local extinction and reignition events $[82,83]$ and, in extreme cases, global blow-off of the flame can be observed. The prediction of such phenomena, that imply transients of the local flame structure, is one of the main challenges of current generation turbulent combustion models since the interaction between turbulence and chemistry has to be accurately captured to have reliable predictions. Although some success in predicting local extinctions has been shown with flamelet-based models [84, 85], methods based on the online solution of the chemistry appear the most appropriate since it is possible to directly take into account the interaction between turbulence and flame structure, with the former directly affecting the transient evolution of the species. Furthermore, the presence of liquid sprays, as in typical gas turbines for aeronautical application, further increases the range of scales and physical processes involved in the combustion process [34] generally making the prediction of the flame behavior more challenging. Evaporation directly interacts with the local flame structure [86, 87] and a reliable numerical method should take into account such interactions.

We must distinguish models that solve for one reacting scalar (such as the progress variable for premixed flames and the progress variable and mixture fraction for non-premixed flames; the mixture fraction is a conserved scalar) and those that solve independent transport equations for many reacting scalars. The former tend to use tabulation, where a laminar flame system or a plug-flow or well-stirred reactor is pre-calculated and the results are stored in a table. In the turbulent flow calculation, one solves for the progress variable, and its reaction rate comes from the table. We could call these approaches as "one degree of freedom", in the sense that the multiple species present in the flow are not allowed to evolve independently in the simulation. However, if one wants a simulation of more general validity, the scalars must be allowed to evolve differently from a pre-supposed connection through a laminar flame structure, and hence many transport equations for many scalars must be solved. This allows a simultaneous online solution of the chemistry and the flow. The online solution of the chemistry is achieved in various turbulent combustion models, but mainly they are based on the transport of the probability density function $[21,22]$ of scalars, the Conditional Moment Closure [28], the Thickened Flame Model [26], and the Eddy Dissipation Concept [32]. 
Over the years, both Lagrangian and Eulerian approaches for the transport of the PDF in the Large-Eddy Simulation framework have been developed. In Lagrangian methods, the PDF transport equation is solved with a Monte Carlo approach featuring stochastic particles solved in a Lagrangian framework [23, 24, 88]. In Eulerian methods [25], the solution of the PDF transport equation is based on the transport of Eulerian Stochastic Fields (SF, e.g. [8991]). The LES-SF approach has been recently developed to include sub-grid fluctuations of quantities related to multi-phase interactions such as evaporation [92] and secondary breakup [93, 93], allowing for a more comprehensive description of the physics of real burners. One of the main advantages of transported PDF methods is that the chemical source term explicitly appears in the formulation and therefore no closure is required. However, mixing models are necessary to close the formulation and their modeling is one of the main challenges of transported PDF approaches [94, 95].

The Conditional Moment Closure (CMC) method [27-29] is another approach that allows direct inclusion of the transient solution of the local flame structure. In LESCMC $[96,97]$ quantities are solved in conditional space. The CMC equations describe the time evolution of the local flame structure with terms representing the effect of turbulent transport, micro-mixing as well as evaporation of liquid fuel. Due to the low level of sub-grid fluctuations of the conditional quantities, first order approximation of the chemical source term may be sufficient to have enough accuracy. Singly conditioned LES-CMC, where the conditional space is described by means of a single sample space variable, has been extensively applied to both non-premixed (e.g. [98-102]) and premixed flames [103, 104]. Furthermore, for cases characterized by imperfect premixing, doubly-conditioned CMC has been developed, recently extended to include spray effects $[105,106]$. The evaporation process introduces further challenges to the simulation. Considering the small size of droplets generated by atomization systems typically used in practical combustors, spray evaporation usually leads to inhomogeneities at the small scales. This affects the scalar dissipation rate at the high wavenumber region of the spectrum, and hence it might not be controlled only by the energy cascade from the large scales. Our modeling capability should be further developed in this area since the scalar dissipation rate is one of the key quantities that affects the evolution of the flame. Similarly to the mixing model in transported PDF methods, in CMC methods the conditional scalar dissipation rate controls the local micro-mixing and proper models are required in order to get the correct effects of mixing and straining on the flame.

The LES-CMC method uses a presumed shape for the probability density function of the mixture fraction. A further evolution of the previous methods is the Multiple Mapping Conditioning [30, 107, 108], which is based on the use of conditional mixing in an attempt of combining the generality of the transported PDF methods with the higher computational efficiency of the CMC approach [109]. In this case, the assumption of a presumed PDF is relaxed, but a mixing model has to be introduced [110]. The formulation, initially developed in the context of gaseous flames, has been further extended to spray flames [109] to include the effects of evaporation in the computation of the local flame structure.

Finally, the Eddy Dissipation Concept $[32,111,112]$ has been used for a variety of low-Da systems and comes in various versions. In short, it assumes that the chemical reaction occurs in "well-mixed" regions of the turbulent eddy, whose volume fraction is given by considering the statistics of turbulent kinetic energy dissipation. These "reactors" have a lifetime given by turbulence theory, and the chemistry is allowed to evolve during this timescale. This model is not very widely used, but nevertheless it is based on an elegant and insightful description of turbulence and eddy structure. It has the potential to capture finite-rate kinetics, but it has not been validated yet as extensively as other models. 
One of the most important challenges for models used in computational combustion is the prediction of pollutants. The design of modern aeroengines is mainly driven by emission requirements. The process of formation and evolution of $\mathrm{NO}$ and soot is generally characterized by time scales larger than the typical chemical timescales associated with the fuel consumption [113-115]. Also in this case, the online solution of the chemistry appears the most promising solution to improve the reliability of the prediction and to avoid the necessity, for example, of introducing different progress variables to account for the slowest processes. In the specific case of soot formation [116-119], the online solution of the chemistry also allows for a more comprehensive description of the entire process compared to typical tabulated chemistry approaches since a two-way coupling between soot and gasphase chemistry can be easily introduced. Further complexity to the simulation is eventually introduced by radiation and wall heat transfer.

\subsection{International workshops}

There are various coordinated activities in the combustion research area, where experimentalists and modellers meet to discuss new target flames, the sub-models needed, and to compare across predictions. Many of the advances in turbulent combustion over the past 20 years have revolved around these activities. We discuss below some of the most prominent ones. It is interesting that these coordinated attempts follow similar efforts in the turbulence modelling community; perhaps the first being the Stanford international competition on CFD predictions of a turbulent boundary layer in the early 1970s.

1. Turbulent Non-Premixed Flames [38]: This is the first international collaborative activity in the turbulent combustion area. It has provided an extraordinary degree of advance for turbulent combustion models suitable for finite-rate kinetic effects (CMC, PDF, flamelet). The key has been a piloted jet flame operated at conditions of progressively higher degree of local extinction, first developed at the University of Sydney. Accurate measurements of subsequent such flames in Sandia National Labs have provided challenging metrics for modellers. It seems that the current generation of advanced models (PDF, CMC, Flamelet) can predict Flame F (the one with the highest degree of extinction) and some derivatives to acceptable accuracy [85, 90, 120-122], but the degree of re-ignition is often not captured very well.

2. Turbulent Premixed Flames [39]: There is less strong coordination among modellers and experimentalists in this Workshop, but the intricacies of turbulent premixed flames are regularly discussed and some target flames (piloted Bunsen; bluff-body; jet in hot products) are being proposed.

3. Turbulent Combustion of Sprays [40]: Piloted jet flames, where the jet is composed of carrier air, prevapourised fuel, and fuel in droplet form, have formed the main target flames of this activity. The flames have been measured at the University of Sydney and have been modelled by many labs. Recent additions are the Rouen flame [123] and a recirculating spray flame from University of Cambridge [124], where various datasets focusing on extinction are available [125]. Here, discussions on atomisation models are necessarily prominent, so the participants to this workshop must also learn about twophase flow. In fact, one of the main uncertainties in the simulation of spray flames in real combustion systems is still related to spray boundary conditions. The atomization process strongly depends on the atomizer configuration as well as on the interactions at the interface between the liquid and the gas phase [126]. Such interactions, which determine instability and the subsequent breakup of the liquid (e.g. prefilming airblast 
systems but also pressure atomizers $[127,128])$, may occur over a wide range of scales and an accurate prediction of the spray characteristics generally requires a detailed simulation of the flow at the atomizer exit and possibly also in the internal channels of the injector (depending on the configuration). Therefore, one of the main objectives for all the experimental dataset included in this workshop is to provide accurate measurements of the spray characteristics (typically velocity and diameter) close to the injection location in order to reduce the uncertainty related to spray boundary conditions. At the same time, numerical models able to predict the spray characteristics after the primary breakup [129-131] are being developed to improve the reliability of the simulations where spray measurements at the injection location are not available. Spray evaporation and droplet dispersion modeling are other important aspects covered in this workshop.

4. Sooting Flames [41]: The production and oxidation of soot is key to the low emission operation of gas turbines and diesel engines and in this Workshop there are a few target flames that can assist the modeller develop appropriate models for these processes. The target flames include: (i) laminar jet flames, which should be used first so as to validate the underlying combustion chemistry and soot models; (ii) turbulent jet flames, which can be used for a first attempt to see the turbulent combustion model behaviour with soot added, and recently (iii) swirl flames with recirculation and hence being more relevant to industrial practice. Motivated by the necessity of developing and validating reliable models for the prediction of soot in practical engines, there is an increased interest in heavy-hydrocarbon flames at engine-relevant conditions. For this reason, counterflow diffusion flames with complex hydrocarbons at high pressure have been recently included as target flames. To improve the understanding of soot formation and its correlation with the mixing field, experimental diagnostics should be further developed, including simultaneous measurements of soot and the main precursors as well as mixture fraction. Furthermore, since practical flames are usually characterized by a highly turbulent environment, the understanding of the interaction between turbulence and soot production and oxidation is a crucial aspect for a reliable and quantitative prediction of the soot level in engines. Development of mixing models as well as chemical mechanisms for complex hydrocarbons at high pressure are important aspects to improve the accuracy of numerical methods. In addition, although in many applications the soot production is often dominated by the surface growth mechanism, there is also interest in the study of 'inception dominated' flames. Such flames enable further validation of inception models, even though for a comprehensive understanding of the inception mechanism very accurate measurements at the nano-scale level are required. This poses further challenges for experimental diagnostics.

5. Engine Combustion Network [42]: The target flames concern injection of a liquid spray in a closed volume and monitoring the autoignition, flame location, droplet dispersion and soot formation as a function of fuel type and ambient parameters (temperature, pressure, oxygen concentration). The experimental results are eminently applicable to new low- $\mathrm{NO}_{\mathrm{x}}$ and low-soot diesel engine technologies and have proven challenging to predict. As always, some models perform better than others for some quantities and care is needed when extrapolating the degree of success to other conditions.

All these activities have dedicated websites, databases available to all for model validation, and involve regular discussions among the participants, hence promoting a collaborative spirit and fast progress in the underlying science. Any researcher in turbulent combustion would benefit from taking a close look. 


\subsection{Examples}

The development of numerical models able to predict finite-rate chemistry effects has been the objective of recent work in many labs. In the following, a summary of some recent achievements is given with the main objective of further highlighting the modeling requirements for a reliable prediction of the behavior of flames of practical interest. Areas where research and development are still necessary will be discussed. The combustion modeling approach used in all the studies presented below is based on Large-Eddy Simulation with the Conditional Moment Closure combustion model. Such studies come from the authors' own research and are selected only as an indication of the type of result currently achievable with turbulent combustion modelling and as a demonstration on how validation is usually performed. Although some considerations are based on the specific requirements of this approach, an attempt is made to make conclusions more general and applicable to the entire area of turbulence combustion modeling.

Before giving some examples, it is important to point out that the simulation of real systems requires several layers of model development and validation. A simplified classification of the steps required for a full validation of modeling capabilities may be based on the level of complexity of the configuration to be investigated: (i) lab-scale flames; (ii) model combustors; (iii) real geometries. It should be noted that this classification also follows the degree of maturity of a given model. Lab-scale flames focus on the key physics that should be captured by a given model. These flames are generally simple but still preserve some fundamental characteristics in terms of fluid dynamics and mixing. The relatively simple configuration generally allows the use of several diagnostics techniques (see Section 2.1) and the generation of an extended database for model validation. The target flames discussed in Section 2.3 usually belong to this category. Once the capability of a model to predict the key physics has been validated in lab-scale configurations, the second step of development requires the application to "Model combustors". In this case, a configuration much closer to the real combustor is considered. Compared to the real combustion system the geometry is still simplified allowing for optical access for the use of diagnostics techniques. However, the geometry of specific elements (e.g. injection system in aeronautical gas turbine combustors) is realistic and the operating conditions are fully representative of the actual system (e.g engine cycle). The simulation of such configurations introduces new challenges, mainly due to the coupling of several fundamental physical processes addressed independently in lab-scale experiments. This step of validation might require further modeling development. The last stage of validation is the application to real engine configurations. In this case, the amount of data available is limited and generally based on point measurements at the exit of the engine or at few accessible locations. In the following, examples of simulations of cases belonging to the first two categories are given. All the lab-scale flames considered here are based on non-premixed configurations.

The capability of the LES-CMC approach to capture local extinction was first validated by Garmory and Mastorakos [121] in the case of a jet flame (Sandia F). The model was then further assessed through the simulation of swirl-stabilised flames [82, 133]. The extinction behavior generally depends on the burner configuration but also on the fuel. Zhang et al. [102] investigated the local extinction of a methane flame with axial fuel injection showing that the LES-CMC approach is able to properly capture the local extinction behavior. The effect of wall heat transfer was also evaluated [132] by developing a model for heat transfer in conditional space. An important piece of validation of LES-CMC as a tool of predictive capability is provided in Ref. [132], where the full blow-off curve was derived from LES (Fig. 1) to acceptable accuracy. 


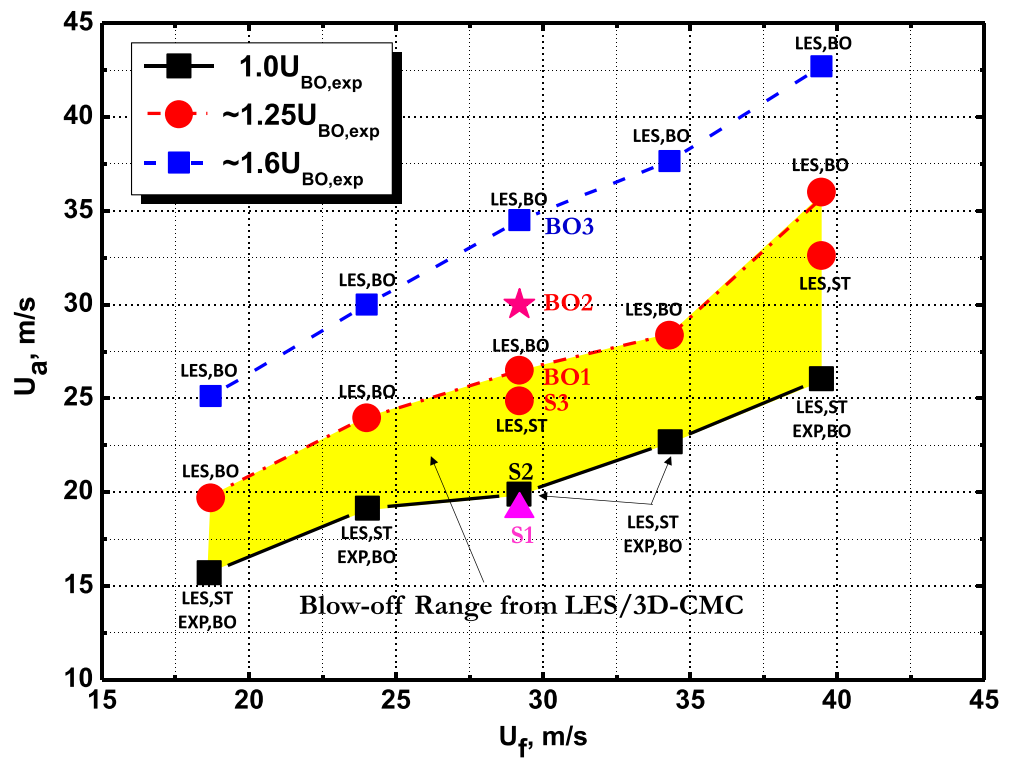

Fig. 1 LES-CMC prediction of the blow-off curve of the burner investigated by Cavaliere et al. [82]. Reproduced from Ref. [132] with permission

This example serves to demonstrate the validation procedure: first you look at a flame that is simple from a fluid mechanical perspective but difficult in terms of combustion and for which a large amount of refined experimental data is available. Following this step (which can also be used for tuning any sub-models), then you look at a flame that has more challenging fluid mechanical features such as swirl, dilution jets, and stagnation points while keeping the focus on the same combustion problem - in the above case, local and global extinction. Similar approaches have been taken by many labs and for many combustion models, although capturing the full blow-off curve in a swirl flame in only now receiving the full attention of modellers.

The presence of liquid fuel introduces further challenges due to the interaction of the flame and mixing field with the evaporation process. Local extinctions in spray flames were

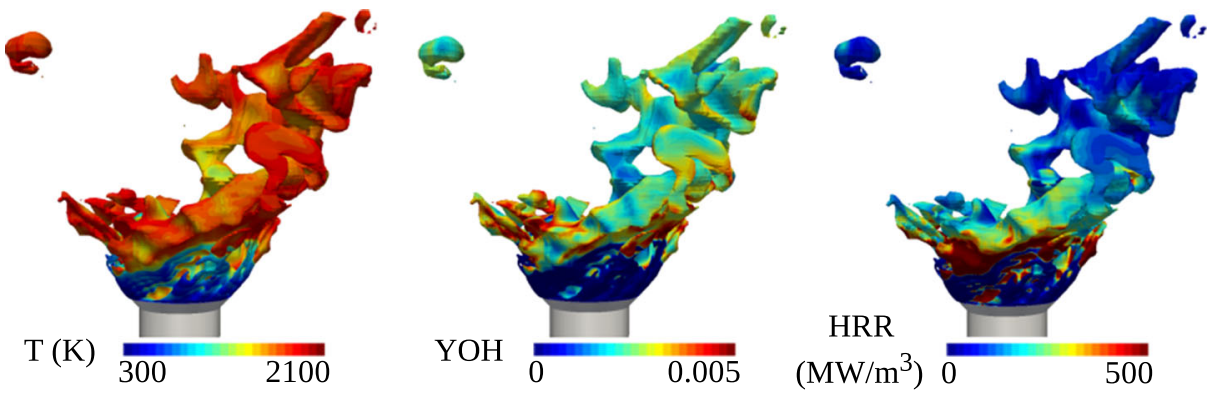

Fig. 2 Isosurface of the stoichiometric mixture fraction coloured with, from left to right, temperature, $\mathrm{OH}$ mass fraction and heat release rate from a LES-CMC simulation of a turbulent spray flame. Reproduced from Ref. [98] with permission 
numerically investigated by Giusti and Mastorakos [98]. Figure 2 shows an example of local extinction in an ethanol spray flame. The isosurface of the stoichiometric mixture fraction presents regions characterized by relatively low temperature and negligible $\mathrm{OH}$ mass fraction and heat release rate denoting absence of reactions. Absence of chemical reactions in the region attached to the bluff-body also indicates lift-off of the flame that for this particular flame is therefore due to local extinction. It is important to point out that localised extinctions are characterized by strong dynamics and, because of turbulent transport and mixing effects, the local flame may exhibit fluctuations with subsequent extinction and reignition events $[98,102]$. Since the lift-off of the flame of Fig. 2 is due to local extinction, the experimental measurement of the probability density function of the lift-off height represents an important metric to assess the capability of a combustion model to capture local extinctions quantitatively. As shown in Fig. 3, where the probability density function of the lift-off height is shown from the simulation and the experiment, it was found [98] that the LES-CMC is a very promising approach for the prediction of local extinction behaviour. Note the use of statistical quantities used for the comparison, and especially the use of the complete PDF; this has become available in the simulations only because LES was used, while it was relatively easy to capture in the experiment through the fast diagnostics that were used. Such degree of validation is needed to build trust in a turbulent combustion model, but is often missing in the literature.

A blow-off transient of the same flame was also investigated by Giusti and Mastorakos [134]. The strong coupling between global extinction and evaporation was highlighted. It was found that the blow-off transient is characterized by an increase of the degree of local extinction with the flame that becomes more and more fragmented. The extent of regions with high temperature reduces as the global extinction progresses and the evaporation rate decreases implying a lower amount of fuel vapour released in the reaction zone. At the same time, the flame moves closer to the injection location with evaporation strongly affecting also the local extinction behaviour. Recently, complete blow-off of a spray combustor has also been attempted with the progress variable-flamelet model [84] and reasonable prediction of the structure of the flame at the blow-off condition was made. In addition, the "Lean Blow-Out" (LBO, as global extinction is known in gas turbine combustion parlance) was simulated and the important role of evaporation in determining the

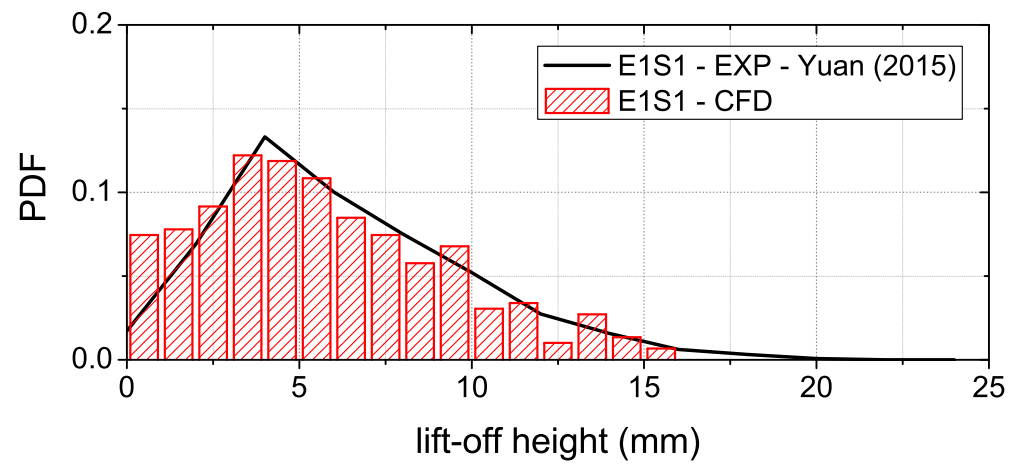

Fig. 3 LES-CMC prediction of the probability density function of the lift-off height of an ethanol spray flame (E1S1) investigated by Yuan et al. [124, 133]. The experimental PDF is based on analysing instantaneous images of the OH-PLIF signal that show where the reaction zone is relative to the bluff body. Reproduced from Ref. [98] with permission 
extinction behavior was also highlighted in this study. Differences between experiments and simulations in terms of LBO limits indicated the necessity of further studies and model development to quantitatively predict the blow-off event [84]. The modelling of the spray, including boundary conditions and multi-component fuel properties, was identified as main source of uncertainty [84]. The strong dependency of the blow-off transient on the spray also suggested that a higher fidelity combustion model that directly includes spray effects could further improve the accuracy of the simulations [84].

As an example of the accuracy and limitations of modern turbulent combustion models to capture emissions, we mention here the simulation by Giusti et al. [77] of an aeroengine model combustor [135] at low-power conditions. The simulation tool was LES-CMC and the main focus of this work was the investigation of soot formation in the near-injector region. Here, the CMC model was coupled with a two-equation model $[117,136,137]$ for soot. Soot formation and evolution is characterized by a strong coupling with the mixing and reacting fields. Turbulent transport is a key element in the soot evolution and approaches that are able to directly include the mixing effects on the flame structure appear necessary [118]. As shown in Fig. 4, the LES-CMC approach was found to be able to capture reasonably well the location of the soot. However, the level of the soot volume fraction is overestimated. Such capability is of crucial importance for the development of new combustion technologies. Further assessment and validation are still necessary to improve the prediction capability at high pressure and for heavy hydrocarbons. From this point of view, it is also important to develop extensive experimental databases at such conditions. The soot production and oxidation paths are still only partly understood. Following the current understanding, PAHs play an important role in soot inception and growth and hence sectional models based on PAHs have been developed (e.g. [138, 139]). Such models require complex chemistry (many species and reactions involved, even for simple hydrocarbons [140]) increasing the computational cost of approaches based on the online solution of the chemistry. However, it should be noted that in the near future, due to regulations that impose limits on soot size, the use of approaches that are able to accurately capture the soot size distribution [141] should be further developed.

Another important field where numerical simulations are becoming extensively used to both assist the design process and improve the physical understanding is the analysis of thermoacoustic stability (e.g. [26, 142-145]) and combustion noise [146, 147]. The simulation of the acoustics generally requires the use of compressible solvers able to capture
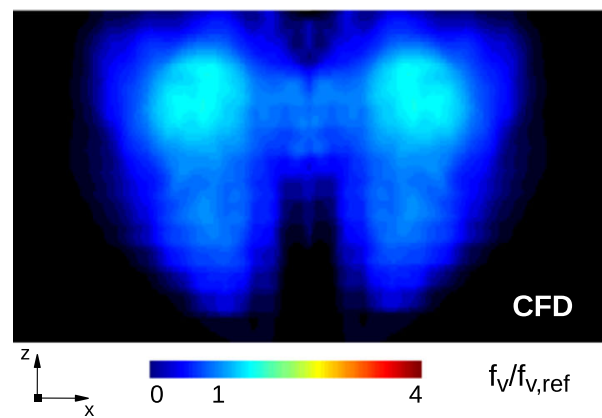

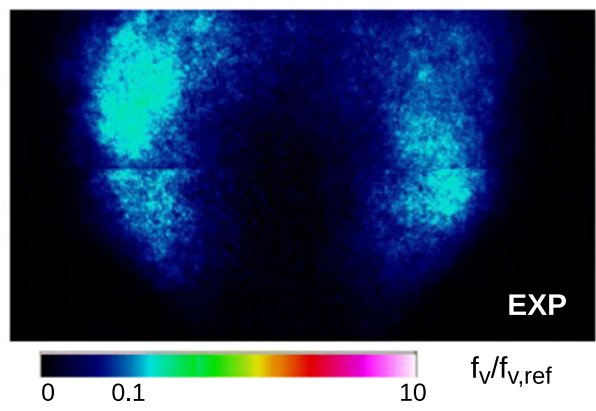

Fig. 4 Left: LES-CMC prediction of the mean soot volume fraction in a model combustor at engine relevant conditions. Right: Soot volume fraction from experiment. Reproduced from Ref. [77] with permission 
the propagation of acoustic waves. Numerical simulations, coupled with system identification techniques [148], can provide further insight into the mechanisms leading to the flame response and help the development of low-order models $[149,150]$ to be used in acoustic network codes. Numerical simulations of realistic combustors $[147,151]$ have been recently used to analyse the transport of combustion inhomogeneities and the effect of the pressure waves generated by their acceleration on both the stability of the system and the noise level. The analysis of dissipation and dispersion of entropy and compositional blobs is a field where accurate numerical simulations can give further insight [152-154]. Limit cycles [155] as well as flame response to high-amplitude perturbations [71, 156], typically characterized by a highly non-linear behaviour, are also important topics for the safe operation of modern engines and advanced numerical simulation can certainly contribute to the development of a better understanding and control of the phenomena [157].

\section{Future Directions}

The turbulent combustion modelling field has seen an unprecedented explosion of activity in the last few years due to the development of faster computers (which allowed the shift to LES and more detailed chemistry), high-speed diagnostics (which allowed studies of flame transients), and the push from industry to use combustion CFD more and more in the design process. In the limit of DNS, a turbulent combustion model becomes unnecessary, since all fluctuations are resolved. In that case, the emphasis would have to be on sprays, soot, radiation, and NO emissions. But is DNS-like resolution feasible in the foreseeable future?

A typical gas turbine combustor at take-off may have incoming air flow at 50-100 m/s, $10 \mathrm{bar}, 600 \mathrm{~K}$, and a typical energy-containing eddy will be of the order of the injector passage, so let us say $30 \mathrm{~mm}$. This gives a turbulent Reynolds number of the order $10^{5}$ and a Kolmogorov scale of $5 \mu \mathrm{m}$. Considering the need to only resolve the turbulence, and using $100 \mathrm{~mm}$ as a typical overall combustor scale, if such a combustor were to be simulated by DNS, we would need of order $10^{13}$ grid nodes. This is 3-4 orders of magnitude larger than the largest billion-node DNS calculation achieved today for research purposes, possible only in very few labs through extensive access to supercomputers and costing many millions of CPU hours. Also, such calculations are done once, after months of planning, and the data are mined for information for years by a large number of $\mathrm{PhD}$ students dedicated to this effort (which is computationally expensive in its own right). This approach cannot be followed in industry for routine design.

The requirement to resolve the reaction zone is different. A kerosene flame at stoichiometry and the above conditions has a thickness of about $30 \mu \mathrm{m}$. A laminar flame code predicts the correct flame speed and turbulent combustion DNS may be considered accurate if there are 10-20 nodes across the reaction zone. This requirement also brings the required resolution from a future combustor DNS down to a few microns. We conclude that DNS cannot be used for routine design purposes in industry for quite a few years.

How about Automatic Mesh Refinement (AMR), which could allow computational resources to be deployed where they are mostly needed, i.e. at the flame? Some labs and some commercial codes throw caution to the wind and use this approach without any turbulent combustion model! Such methods have been touted as adequate for some lab-scale problems, although there has not been any focused and as extensive validation for finite-rate kinetic effects as for the other models. For diesel engines, it has been shown that such practices may cause large errors in the prediction of the soot formation regions [158]. So what merit may be in such approaches, which some propose as a way to introduce more detailed 
chemistry into the calculation, without the computational penalty associated with a proper turbulent combustion model?

A non-premixed flame eventually may become wide relative to the eddy scales as the mixture fraction fluctuations decay and good mixing is achieved far from the injection point. In such regions, there is less need for an accurate turbulent reaction model because the degree of micromixing is low. But in the same combustor, there will be regions with very high stretch or large mixture fraction fluctuations and those regions will necessitate a sub-grid model. The LES-CMC approach presented previously takes this into account by developing unstructured finite-volume formulations, which allows many CMC nodes where they are needed. The Thickened Flame model [26] also allows a different "Thickening Factor" at different regions in space. The flamelet and PDF methods can also cope. Approaches, however, with no turbulent combustion model are doomed to fail at crucial regions of the combustor, unless they achieve DNS-like resolution of both the reaction zone and the turbulence.

Fuel flexibility is another important aspect of the current trend for the development of combustion devices. In engine applications, generally complex fuels such as kerosene and diesel are used. In evaluating the performance of new surrogates and blends, it has become important to improve the modelling of the evaporation of multicomponent fuels [159]. Complex fuels also require detailed chemical mechanisms, especially in the case finite-rate chemistry effects and emissions are to be predicted. However, the computational cost of methods based on the online solution of the chemistry scales directly with the number of species involved. Therefore, to make the computational cost affordable for cases of practical interest, methods for chemistry reduction [160-162] should be explored more. Recently, there has been increasing interest also in the so called "nanofuels" [163, 164] where smallsize additives (generally in the form of nanoparticles) are added to the fuel to improve some of its characteristics. This is a flourishing area where much effort is still needed both in terms of modelling and fundamental understanding.

In the future, and as computational power gets cheaper, it is expected that we will see more and more emphasis on using LES with advanced combustion models and more and more detailed chemistry for problems closer and closer to reality. Emphasis on sprays, soot, mixed-regime combustion, and high pressures is necessary. On the experimental front, diagnostics are being developed that can probe the local temperature and species concentrations in ever more complex problems, as in sprays and combustors at realistic conditions and it is expected that the community will see more such examples.

\section{Conclusions}

The huge rise in computational power and developments in laser diagnostics in the past few years have resulted in major advances in the scope and extent of validation of combustion CFD, which can now be implemented by industry to predict qualitative trends. The development of fast-response planar diagnostics has allowed very thorough validation of combustion LES and new insights into flame transients, such as those occurring during local and global extinction and thermoacoustics. However, the predictions are not fully trustworthy yet, not least because of the spray, chemistry, and turbulent combustion models that are still needed in the context of LES, despite the smaller grid sizes. All turbulent combustion sub-grid models still include some parameters that can reflect how micro-mixing affects the reaction zone (e.g. the scalar dissipation for CMC; the mixing timescale for the transported PDF; the thickening factor for the Thickened Flame Model etc.) and this aspect still 
needs validation and further development when sprays are included. Finally, multi-physics methods for soot must be developed.

Acknowledgements EM wishes to acknowledge the huge contribution that the late Prof. R.W. Bilger made to the author's understanding of turbulent combustion modelling over a long period of very fruitful collaboration. We also wish to thank Rolls-Royce Group for their long-term financial assistance on experiments and modelling of spray flames.

Funding Information This study was funded by Rolls-Royce Plc (GB) for a Senior Research Associate position.

\section{Compliance with Ethical Standards}

Conflict of interests The authors declare that they have no conflict of interest.

Open Access This article is distributed under the terms of the Creative Commons Attribution 4.0 International License (http://creativecommons.org/licenses/by/4.0/), which permits unrestricted use, distribution, and reproduction in any medium, provided you give appropriate credit to the original author(s) and the source, provide a link to the Creative Commons license, and indicate if changes were made.

\section{References}

1. Gohardani, A.S., Doulgeris, G., Singh, R.: Challenges of future aircraft propulsion: a review of distributed propulsion technology and its potential application for the all electric commercial aircraft. Prog. Aerosp. Sci. 47(5), 369-391 (2011)

2. Whurr, J., Beecroft, P.: Vision 20: Rolls-royce's long term civil aircraft propulsion system concept and technology strategy. In: Proceedings of ISABE 2017 manchester 3-8 sept (2017)

3. Brelje, B.J., Martins, J.R.: Electric, hybrid, and turboelectric fixed-wing aircraft: a review of concepts, models, and design approaches. Prog. Aerosp. Sci. 104, 1-19 (2019)

4. Geer, A.: The Rolls-Royce Advance3 Project - Proving our Future Core. In: Proceedings of ISABE 2017 Manchester 3-8 Sept (2017)

5. Gnadt, A.R., Speth, R.L., Sabnis, J.S., Barrett, S.R.: Technical and environmental assessment of allelectric 180-passenger commercial aircraft. Prog. Aerosp. Sci. 105, 1-30 (2019)

6. Mitchell, R., Whitehead, M.: The Rolls-Royce UltraFanß Engine: Delivering the next generation of aerospace propulsion system. In: Proceedings of ISABE 2017 Manchester 3-8 Sept (2017)

7. Pornet, C., Isikveren, A.: Conceptual design of hybrid-electric transport aircraft. Prog. Aerosp. Sci. 79, 114-135 (2015)

8. Echekki, T., Mastorakos, E.: Turbulent Combustion Modeling: Advances, New Trends and Perspectives. Springer, Netherlands (2011)

9. Damköhler, G.: Der einfluss der turbulenz auf die flammengeschwindigkeit in gasgemischen. Z. Elektrochem. 46, 601-652 (1947)

10. Bilger, R.W.Libby, P.A., Williams, F.A. (eds.): Turbulent flows with non-premixed reactants. Springer, Berlin (1980)

11. Hawthorne, W., Weddell, D., Hottel, H.: Mixing and combustion in turbulent gas jets. Symposium on Combustion and Flame, and Explosion Phenomena 3(1), 266-288 (1948)

12. Spalding, D.B.: Combustion and mass transfer. Pergamon press (1979)

13. Bilger, R.W.: Structure of diffusion flames. Combust. Sci. Technol. 13, 155-170 (1976)

14. Spalding, D.B.: Mixing and chemical reaction in steady confined turbulent flames. Proc. Combust. Inst. 13, 649-657 (1971)

15. Magnussen, B.F., Hjertager, B.H.: On mathematical modelling of turbulent combustion with special emphasis on soot formation and combustion. Proc. Combust. Inst. 16, 719-727 (1977)

16. Byggstoyl, S., Magnussen, B.F.: A model for flame extinction in turbulent flow. In: Proceedings of the 4th Symposium on Turbulent Shear Flows, p. 10.32. Karlsruhe (1983)

17. Chakravarty, A., Lockwood, F.C., Sinicropi, G.: The prediction of burner stability limits. Combust. Sci. Technol. 42, 67-86 (1984) 
18. Bradley, D., Gaskell, P.H., Gu, X.J.: The mathematical modeling of liftoff and blowoff of turbulent non-premixed methane jet flames at high strain rates. Proc. Combust. Inst. 27, 1199-1206 (1998)

19. Bray, K.N.C., Libby, P.A., Moss, J.B.: Unified modelling approach for premixed turbulent combustion part 1 - general formulation. Combust. Flame 61, 87-102 (1985)

20. Peters, N.: Turbulent combustion. Cambridge University Press (2000)

21. Dopazo, C., O'Brien, E.E.: An approach to the autoignition of a turbulent mixture. Acta Astronaut. 1, 1239-1266 (1974)

22. Pope, S.B.: PDF Methods for turbulent reacting flows. Prog. Energy Combust. Sci. 11, 119-192 (1985)

23. Lindstedt, R.P., Vaos, E.M.: Transported pdf modelling of high-Reynolds-Number premixed turbulent flames. Combust. Flame 145, 495-511 (2005)

24. Pope, S.B.: Lagrangian PDF methods for turbulent flows. Annu. Rev. Fluid Mech. 26, 23-64 (1994)

25. Valiño, L.: A field Monte Carlo formulation for calculating the probability density function of a single scalar in a turbulent flow. Flow Turbul. Combust. 60, 157-172 (1998)

26. Poinsot, T.: Prediction and control of combustion instabilities in real engines. Proc. Combust. Inst. 36(1), 1-28 (2017)

27. Bilger, R.W.: Conditional moment closure for turbulent reacting flow. Phys. Fluids A 5(2), 436-444 (1993)

28. Klimenko, A., Bilger, R.: Conditional moment closure for turbulent combustion. Prog. Energy Combust. Sci. 25(6), 595-687 (1999)

29. Klimenko, A.Y., Bilger, R.W.: Conditional moment closure of turbulent combustion. Prog. Energy Combust. Sci. 25, 595-687 (1999)

30. Klimenko, A.Y., Pope, S.B.: The modeling of turbulent reactive flows based on multiple mapping conditioning. Phys. Fluids 15(7), 1907-1925 (2003)

31. Kronenburg, A., Cleary, M.: Multiple mapping conditioning for flames with partial premixing. Combust. Flame 155(1), 215-231 (2008)

32. Parente, A., Malik, M.R., Contino, F., Cuoci, A., Dally, B.B.: Extension of the Eddy Dissipation Concept for turbulence/chemistry interactions to MILD combustion. Fuel 163, 98-111 (2016)

33. Bilger, R., Pope, S., Bray, K., Driscoll, J.: Paradigms in turbulent combustion research. Proc. Combust. Inst. 30, 21-42 (2005)

34. Jenny, P., Roekaerts, D., Beishuizen, N.: Modeling of turbulent dilute spray combustion. Prog. Energy Combust. Sci. 38(6), 846-887 (2012)

35. Mastorakos, E.: Ignition of turbulent non-premixed flames. Prog. Energy Combust. Sci. 35(1), 57-97 (2009)

36. Mastorakos, E.: Forced ignition of turbulent spray flames. Proc. Combust. Inst. 36(2), 2367-2383 (2017)

37. Masri, A.R., Kalt, P.A.M., Barlow, R.S.: The compositional structure of swirl-stabilised turbulent nonpremixed flames. Combust. Flame 137, 1-37 (2004)

38. Turbulent Non-premixed Flame workshop: http://www.sandia.gov/TNF/abstract.html

39. Turbulent Premixed Flame workshop: https://sites.google.com/a/umich.edu/premix-turbulent-flame/ 16th-ptf-dublin-1

40. Turbulent Combustion of Sprays workshop: https://wwwproxy.iwr.uni-heidelberg.de/conferences/tcs/

41. International Sooting Flame workshop: https://www.adelaide.edu.au/cet/isfworkshop/

42. Engine Combustion Network: https://ecn.sandia.gov/

43. Gaydon, A.G., Wolfhard, H.G.: Flames, their structure, radiation, and temperature. Halsted Press (1979)

44. Becker, H.A.: Physical Probes. In: Taylor, A.M.K.P. (ed.) Instrumentation for Flows with Combustion, pp. 53-112. Academic Press, Cambridge (1993)

45. Heitor, M.V., Stårner, S.H., Taylor, A.M.K.P., Whitelaw, J.H.: Velocity, size and turbulent flux measurements by Laser-Doppler Velocimetry. In: Taylor, A.M.K.P. (ed.) Instrumentation for Flows with Combustion, pp. 113-250. Academic Press, Cambridge (1993)

46. Eckbreth, A.C. Laser Diagnostics for Combustion Temperature and Species, 2nd edn. Taylor and Francis, New York (1996)

47. Kohse-Höinghaus, K., Barlow, R.S., Aldén, M., Wolfrum, J.: Combustion at the focus: laser diagnostics and control. Proc. Combust. Inst. 31, 89-123 (2005)

48. Shultz, C., Sick, V.: Tracer LIF diagnostics: quantitative measurement of fuel concentration, temperature and fuel/air ratio in practical combustion systems. Prog. Energy Combust. Sci. 31, 75-121 (2005)

49. Instrumentation for Flows with Combustion. In: Taylor, A.M.K.P. (ed.) Academic Press, Cambridge (1993)

50. Magnotti, G., Barlow, R.: Dual-resolution raman spectroscopy for measurements of temperature and twelve species in hydrocarbon-air flames. Proc. Combust. Inst. 36(3), 4477-4485 (2017) 
51. Meier, W., Dem, C., Arndt, C.: Mixing and reaction progress in a confined swirl flame undergoing thermo-acoustic oscillations studied with laser raman scattering. Exp. Therm. Fluid Sci. 73, 71-78 (2016). Special issue on Ninth Mediterranean Combustion Symposium

52. Ayoola, B.O., Balachandran, R., Frank, J.H., Mastorakos, E., Kaminski, C.: Spatially resolved heat release rate measurements in turbulent premixed flames. Combust. Flame 144, 1-16 (2006)

53. Hardalupas, Y., Orain, M.: Local measurements of the time-dependent heat release rate and equivalence ratio using chemiluminescent emission from a flame. Combust. Flame 139(3), 188-207 (2004)

54. Panoutsos, C., Hardalupas, Y., Taylor, A.: Numerical evaluation of equivalence ratio measurement using $\mathrm{OH}$ and $\mathrm{CH}$ chemiluminescence in premixed and non-premixed methane-air flames. Combust. Flame 156(2), 273-291 (2009)

55. Kheirkhah, S., Cirtwill, J.D.M., Saini, P., Venkatesan, K.: Steinberg, A.M.: Dynamics and mechanisms of pressure, heat release rate, and fuel spray coupling during intermittent thermoacoustic oscillations in a model aeronautical combustor at elevated pressure. Combust. Flame 185, 319-334 (2017)

56. Li, J., Durox, D., Richecoeur, F., Schuller, T.: Analysis of chemiluminescence, density and heat release rate fluctuations in acoustically perturbed laminar premixed flames. Combust. Flame 162(10), 39343945 (2015)

57. Meier, W., Weigand, P., Duan, X., Giezendanner-Thoben, R.: Detailed characterization of the dynamics of thermoacoustic pulsations in a lean premixed swirl flame. Combust. Flame 150(1), 2-26 (2007)

58. Worth, N.A., Dawson, J.R.: Tomographic reconstruction of $\mathrm{OH}^{*}$ chemiluminescence in two interacting turbulent flames. Meas. Sci. Technol. 24(2), 024,013 (2012)

59. Dreizler, A., B'ohm, B.: Advanced laser diagnostics for an improved understanding of premixed flamewall interactions. Proc. Combust. Inst. 35(1), 37-64 (2015)

60. Kariuki, J., Dowlut, A., Yuan, R., Balachandran, R., Mastorakos, E.: Heat release imaging in turbulent premixed methane-air flames close to blow-off. Proc. Combust. Inst. 35(2), 1443-1450 (2015)

61. Bohon, M.D., Guiberti, T.F., Roberts, W.L.: PLIF Measurements of non-thermal NO concentrations in alcohol and alkane premixed flames. Combust. Flame 194, 363-375 (2018)

62. Geigle, K.P., O'Loughlin, W., Hadef, R., Meier, W.: Visualization of soot inception in turbulent pressurized flames by simultaneous measurement of laser-induced fluorescence of polycyclic aromatic hydrocarbons and laser-induced incandescence, and correlation to $\mathrm{OH}$ distributions. Appl. Phys. B 119(4), 717-730 (2015)

63. Mulla, I.A., Dowlut, A., Hussain, T., Nikolaou, Z.M., Chakravarthy, S.R., Swaminathan, N., Balachandran, R.: Heat release rate estimation in laminar premixed flames using laser-induced fluorescence of $\mathrm{CH} 2 \mathrm{o}$ and $\mathrm{H}$-atom. Combust. Flame 165, 373-383 (2016)

64. Kiefer, J., Li, Z., Seeger, T., Leipertz, A., Aldén, M.: Planar laser-induced fluorescence of HCO for instantaneous flame front imaging in hydrocarbon flames. Proc. Combust. Inst. 32(1), 921-928 (2009)

65. Cutcher, H.C., Barlow, R.S., Magnotti, G., Masri, A.R.: Statistics of scalar dissipation and reaction progress in turbulent flames with compositional inhomogeneities. Combust. Flame 194, 439-451 (2018)

66. Dennis, C.N., Slabaugh, C.D., Boxx, I.G., Meier, W., Lucht, R.P.: $5 \mathrm{kHz}$ thermometry in a swirlstabilized gas turbine model combustor using chirped probe pulse femtosecond CARS. Part 1: Temporally resolved swirl-flame thermometry. Combust. Flame 173, 441-453 (2016)

67. Lowe, A., Thomas, L., Satija, A., Lucht, R., Masri, A.: Chirped-probe-pulse femtosecond CARS thermometry in turbulent spray flames. Proc. Combust. Inst. 37(2), 1383-1391 (2019)

68. Lowe, A., Thomas, L.M., Satija, A., Lucht, R.P., Masri, A.R.: Five kHz thermometry in turbulent spray flames using chirped-probe-pulse femtosecond CARS, part II: Structure of reaction zones. Combust. Flame 200, 417-432 (2019)

69. Thomas, L.M., Lowe, A., Satija, A., Masri, A.R., Lucht, R.P.: Five kHz thermometry in turbulent spray flames using chirped-probe pulse femtosecond CARS, part I: Processing and interference analysis. Combust. Flame 200, 405-416 (2019)

70. Evans, M., Sidey, J., Ye, J., Medwell, P., Dally, B., Mastorakos, E.: Temperature and reaction zone imaging in turbulent swirling dual-fuel flames. Proc. Combust. Inst. 37(2), 2159-2166 (2019)

71. Kypraiou, A.M., Giusti, A., Allison, P.M., Mastorakos, E.: Dynamics of acoustically forced nonpremixed flames close to blow-off. Exp. Therm. Fluid Sci. 95, 81-87 (2018). Tenth Mediterranean Combustion Symposium

72. Aoki, K., Shimura, M., Ogawa, S., Fukushima, N., Naka, Y., Nada, Y., Tanahashi, M., Miyauchi, T.: Short- and long-term dynamic modes of turbulent swirling premixed flame in a cuboid combustor. Proc. Combust. Inst. 35(3), 3209-3217 (2015)

73. Ayache, S., Mastorakos, E.: Investigation of the "TECFLAM" non-premixed flame using large eddy simulation and proper orthogonal decomposition. Flow Turbul. Combust. 90(2), 219-241 (2013)

74. Duwig, C., Iudiciani, P.: Extended proper orthogonal decomposition for analysis of unsteady flames. Flow Turbul. Combust. 84(1), 25 (2009) 
75. Kostka, S., Lynch, A.C., Huelskamp, B.C., Kiel, B.V., Gord, J.R., Roy, S.: Characterization of flameshedding behavior behind a bluff-body using proper orthogonal decomposition. Combust. Flame 159(9), 2872-2882 (2012)

76. Roy, S., Hua, J.C., Barnhill, W., Gunaratne, G.H., Gord, J.R.: Deconvolution of reacting-flow dynamics using proper orthogonal and dynamic mode decompositions. Phys. Rev. E 91(013), 001 (2015)

77. Giusti, A., Mastorakos, E., Hassa, C., Heinze, J., Magens, E., Zedda, M.: Investigation of flame structure and soot formation in a single sector model combustor using experiments and numerical simulations based on the large eddy Simulation/Conditional moment closure approach. J. Eng. Gas. Turbines Power 140(6) (2018)

78. Schroll, M., Doll, U., Stockhausen, G., Meier, U., Willert, C., Hassa, C., Bagchi, I.: Flow field characterization at the outlet of a lean burn Single-Sector combustor by Laser-Optical methods. J. Eng. Gas Turbines Power 139(1), 0115,031-9 (2017)

79. Stöhr, M., Geigle, K., Hadef, R., Boxx, I., Carter, C., Grader, M., Gerlinger, P.: Time-resolved study of transient soot formation in an aero-engine model combustor at elevated pressure. Proc. Combust. Inst. 37(4), 5421-5428 (2019)

80. Lucca-Negro, O., O’Doherty, T.: Vortex breakdown: a review. Prog. Energy Combust. Sci. 27(4), 431481 (2001)

81. Syred, N.: A review of oscillation mechanisms and the role of the precessing vortex core (PVC) in swirl combustion systems. Prog. Energy Combust. Sci. 32(2), 93-161 (2006)

82. Cavaliere, D.E., Kariuki, J., Mastorakos, E.: A comparison of the Blow-Off behaviour of Swirl-Stabilized premixed, Non-Premixed and spray flames. Flow Turbul. Combust. 91(2), 347-372 (2013)

83. Yuan, R., Kariuki, J., Dowlut, A., Balachandran, R., Mastorakos, E.: Reaction zone visualisation in swirling spray n-heptane flames. Proc. Combust. Inst. 35(2), 1649-1656 (2015)

84. Esclapez, L., Ma, P.C., Mayhew, E., Xu, R., Stouffer, S., Lee, T., Wang, H., Ihme, M.: Fuel effects on lean blow-out in a realistic gas turbine combustor. Combust. Flame 181, 82-99 (2017)

85. Ihme, M., Pitsch, H.: Prediction of extinction and reignition in nonpremixed turbulent flames using a flamelet/progress variable model: 2. Application in LES of Sandia flames D and E. Combust. Flame 155(1-2), 90-107 (2008)

86. Giusti, A., Sidey, J.A., Borghesi, G., Mastorakos, E.: Simulations of droplet combustion under gas turbine conditions. Combust. Flame 184, 101-116 (2017)

87. Olguin, H., Gutheil, E.: Influence of evaporation on spray flamelet structures. Combust. Flame 161(4), 987-996 (2014)

88. Haworth, D.: Progress in probability density function methods for turbulent reacting flows. Prog. Energy Combust. Sci. 36(2), 168-259 (2010)

89. Jones, W., Marquis, A., Vogiatzaki, K.: Large-eddy simulation of spray combustion in a gas turbine combustor. Combust. Flame 161(1), 222-239 (2014)

90. Jones, W., Prasad, V.: Large Eddy Simulation of the Sandia Flame Series (D-F) using the Eulerian stochastic field method. Combust. Flame 157(9), 1621-1636 (2010)

91. Jones, W.P., Tyliszczak, A.: Large eddy simulation of spark ignition in a gas turbine combustor. Flow Turbul. Combust. 85(3), 711-734 (2010)

92. Bini, M., Jones, W.: Large Eddy Simulation of an evaporating acetone spray. Int. J. Heat Fluid Fl. 30(3), 471-480 (2009)

93. Jones, W., Marquis, A., Noh, D.: A stochastic breakup model for Large Eddy Simulation of a turbulent two-phase reactive flow. Proc. Combust. Inst. 36(2), 2559-2566 (2017)

94. Krisman, A., Tang, J.C., Hawkes, E.R., Lignell, D.O., Chen, J.H.: A DNS evaluation of mixing models for transported PDF modelling of turbulent nonpremixed flames. Combust. Flame 161(8), 2085-2106 (2014)

95. Ren, Z., Pope, S.B.: An investigation of the performance of turbulent mixing models. Combust. Flame 136(1), 208-216 (2004)

96. Mortensen, M., Bilger, R.W.: Derivation of the conditional moment closure equations for spray combustion. Combust. Flame 156(1), 62-72 (2009)

97. Navarro-Martinez, S., Kronenburg, A., Di Mare, F.: Conditional moment closure for large eddy simulations. Flow Turbul. Combust. 75(1-4), 245-274 (2005)

98. Giusti, A., Mastorakos, E.: Detailed chemistry LES/CMC simulation of a swirling ethanol spray flame approaching blow-off. Proc. Combust. Inst. 36(2), 2625-2632 (2017)

99. Navarro-Martinez, S., Kronenburg, A.: LES-CMC Simulations of a lifted methane flame. Proc. Combust. Inst. 32(1), 1509-1516 (2009)

100. Ukai, S., Kronenburg, A., Stein, O.: Large eddy simulation of dilute acetone spray flames using CMC coupled with tabulated chemistry. Proc. Combust. Inst. 35(2), 1667-1674 (2015) 
101. Ukai, S., Kronenburg, A., Stein, O.T.: Simulation of dilute acetone spray flames with LES-CMC using two conditional moments. Flow Turbul. Combust. 93(3), 405-423 (2014)

102. Zhang, H., Garmory, A., Cavaliere, D.E., Mastorakos, E.: Large Eddy Simulation/Conditional Moment Closure modeling of swirl-stabilized non-premixed flames with local extinction. Proc. Combust. Inst. 35(2), 1167-1174 (2015)

103. Farrace, D., Chung, K., Bolla, M., Wright, Y.M., Boulouchos, K., Mastorakos, E.: A LES-CMC formulation for premixed flames including differential diffusion. Combust. Theory Model. 22(3), 411-431 (2018)

104. Farrace, D., Chung, K., Pandurangi, S.S., Wright, Y.M., Boulouchos, K., Swaminathan, N.: Unstructured LES-CMC modelling of turbulent premixed bluff body flames close to blow-off. Proc. Combust. Inst. 36(2), 1977-1985 (2017)

105. Sitte, M.P., Mastorakos, E.: Modelling of spray flames with doubly conditional moment closure. Flow Turbul. Combust. 99(3), 933-954 (2017)

106. Sitte, M.P., Mastorakos, E.: Large Eddy Simulation of a spray jet flame using Doubly Conditional Moment Closure. Combust. Flame 199, 309-323 (2019)

107. Cleary, M., Kronenburg, A.: Multiple mapping conditioning for extinction and reignition in turbulent diffusion flames. Proc. Combust. Inst. 31(1), 1497-1505 (2007)

108. Salehi, F., Cleary, M., Masri, A., Ge, Y., Klimenko, A.: Sparse-lagrangian MMC simulations of an n-dodecane jet at engine-relevant conditions. Proc. Combust. Inst. 36(3), 3577-3585 (2017)

109. Khan, N., Cleary, M.J., Stein, O.T., Kronenburg, A.: A two-phase MMC-LES model for turbulent spray flames. Combust. Flame 193, 424-439 (2018)

110. Varna, A., Cleary, M., Hawkes, E.: A multiple mapping conditioning mixing model with a mixturefraction like reference variable. Part 1: Model derivation and ideal flow test cases. Combust. Flame 181, 342-353 (2017)

111. Bösenhofer, M., Wartha, E.M., Jordan, C., Harasek, M.: The eddy dissipation Concept-Analysis of different fine structure treatments for classical combustion. Energies 11(7) (2018)

112. Magnussen, B.F.: The Eddy Dissipation Concept: A bridge between science and technology. In: ECCOMAS Thematic Conference on Computational Combustion, Lisbon, June 21-24 (2005)

113. Commodo, M., Falco, G.D., Bruno, A., Borriello, C., Minutolo, P., D’Anna, A.: Physicochemical evolution of nascent soot particles in a laminar premixed flame: from nucleation to early growth. Combust. Flame 162(10), 3854-3863 (2015)

114. Correa, S.M.: A review of NOx formation under gas-turbine combustion conditions. Combust. Sci. Technol. 87(1-6), 329-362 (1993)

115. Jaravel, T., Riber, E., Cuenot, B., Bulat, G.: Large Eddy Simulation of an industrial gas turbine combustor using reduced chemistry with accurate pollutant prediction. Proc. Combust. Inst. 36(3), 3817-3825 (2017)

116. Kennedy, I.M.: Models of soot formation and oxidation. Prog. Energy Combust. Sci. 23(2), 95-132 (1997)

117. Kronenburg, A., Bilger, R., Kent, J.: Modeling soot formation in turbulent methane-air jet diffusion flames. Combust. Flame 121(1-2), 24-40 (2000)

118. Lindstedt, R., Louloudi, S.: Joint-scalar transported PDF modeling of soot formation and oxidation. Proc. Combust. Inst. 30(1), 775-783 (2005)

119. Sewerin, F., Rigopoulos, S.: An LES-PBE-PDF approach for predicting the soot particle size distribution in turbulent flames. Combust. Flame 189, 62-76 (2018)

120. Barlow, R., Ozarovsky, H., Karpetis, A., Lindstedt, R.: Piloted jet flames of CH4/h2/air: Experiments on localized extinction in the near field at high Reynolds numbers. Combust. Flame 156(11), 2117-2128 (2009)

121. Garmory, A., Mastorakos, E.: Capturing localised extinction in Sandia Flame F with LES-CMC. Proc. Combust. Inst. 33(1), 1673-1680 (2011)

122. Garmory, A., Mastorakos, E.: Numerical simulation of oxy-fuel jet flames using unstructured LESCMC. Proc. Combust. Inst. 35(2), 1207-1214 (2015)

123. Verdier, A., Santiago, J.M., Vandel, A., Saengkaew, S., Cabot, G., Grehan, G., Renou, B.: Experimental study of local flame structures and fuel droplet properties of a spray jet flame. Proc. Combust. Inst. 36(2), 2595-2602 (2017)

124. Yuan, R., Kariuki, J., Mastorakos, E.: Measurements in swirling spray flames at blow-off. Int.j.spray Combust 0(0) (2018)

125. The Cambridge Flame Data Reporsitory: http://swirl-flame.eng.cam.ac.uk/

126. Lefebvre, A.H.: Atomization and sprays. Taylor and Francis (1989)

127. Dumouchel, C.: On the experimental investigation on primary atomization of liquid streams. Exp. Fluids 45(3), 371-422 (2008) 
128. Sirignano, W., Mehring, C.: Review of theory of distortion and disintegration of liquid streams. Prog. Energy Combust. Sci. 26(4), 609-655 (2000)

129. Duret, B., Reveillon, J., Menard, T., Demoulin, F.: Improving primary atomization modeling through dns of two-phase flows. Int. J. Multiphas Flow 55, 130-137 (2013)

130. Koch, R., Braun, S., Wieth, L., Chaussonnet, G., Dauch, T., Bauer, H.J.: Prediction of primary atomization using smoothed particle hydrodynamics. Eur. J. Mech. B-Fluid 61, 271-278 (2017)

131. Sauer, B., Sadiki, A., Janicka, J.: Embedded DNS concept for simulating the primary breakup of an airblast atomizer. Atomization Sprays 26(3), 187-215 (2016)

132. Zhang, H., Mastorakos, E.: Prediction of global extinction conditions and dynamics in swirling nonpremixed flames using LES/CMC modelling. Flow Turbul. Combust. 96(4), 863-889 (2016)

133. Yuan, R.: Measurements in Swirl-stabilised Spray Flames at Blow-off. Ph.D. thesis, University of Cambridge (2015)

134. Giusti, A., Mastorakos, E.: Numerical investigation into the blow-off behaviour of swirling spray flames using the LES/CMC approach. In: Proceeding of the ETMM-11 (2016)

135. Schneider, D., Meier, U., Quade, W., Koopman, J., Aumeier, T., Langfeld, A., Behrendt, T., Hassa, C., Rackwitz, L.: A new test rig for laser optical investigations of lean jet burners. In: Proceedings of the 27th International Congress of the Aeronautical Sciences (2010)

136. Bolla, M., Wright, Y.M., Boulouchos, K., Borghesi, G., Mastorakos, E.: Soot formation modeling of nheptane sprays under diesel engine conditions using the conditional moment closure approach. Combust. Sci. Technol 185(5) (2013)

137. Leung, K., Lindstedt, R., Jones, W.: A simplified reaction mechanism for soot formation in nonpremixed flames. Combust. Flame 87(3), 289-305 (1991)

138. Eberle, C., Gerlinger, P., Aigner, M.: A sectional PAH model with reversible PAH chemistry for CFD soot simulations. Combust. Flame 179, 63-73 (2017)

139. Sirignano, M., Kent, J., D’Anna, A.: Modeling formation and oxidation of soot in nonpremixed flames. Energy Fuel 27(4), 2303-2315 (2013)

140. Slavinskaya, N.A., Riedel, U., Dworkin, S.B., Thomson, M.J.: Detailed numerical modeling of PAH formation and growth in non-premixed ethylene and ethane flames. Combust. Flame 159(3), 979-995 (2012)

141. Rigopoulos, S.: Population balance modelling of polydispersed particles in reactive flows. Prog. Energy Combust. Sci. 36(4), 412-443 (2010)

142. Huang, Y., Sung, H.G., Hsieh, S.Y., Yang, V.: Large-Eddy Simulation of Combustion Dynamics of Lean-Premixed Swirl-Stabilized Combustor. J. Prop. Power 19(5), 782-794 (2003)

143. Huang, Y., Yang, V.: Dynamics and stability of lean-premixed swirl-stabilized combustion. Prog. Energy Combust. Sci. 35(4), 293-364 (2009)

144. Kraus, C., Selle, L., Poinsot, T.: Coupling heat transfer and large eddy simulation for combustion instability prediction in a swirl burner. Combust. Flame 191, 239-251 (2018)

145. Wolf, P., Staffelbach, G., Gicquel, L.Y., Müller, J.D., Poinsot, T.: Acoustic and Large Eddy Simulation studies of azimuthal modes in annular combustion chambers. Combust. Flame 159(11), 3398-3413 (2012)

146. Dowling, A.P., Mahmoudi, Y.: Combustion noise. Proc. Combust. Inst. 35(1), 65-100 (2015)

147. Giusti, A., Magri, L., Zedda, M.: Flow inhomogeneities in a realistic aeronautical gas-turbine combustor: formation, evolution and indirect noise. J. Eng Gas Turbines Power 141(1) (2019)

148. Polifke, W.: Black-box system identification for reduced order model construction. Ann. Nucl. Energy 67, 109-128 (2014)

149. Föller, S., Polifke, W.: Identification of aero-acoustic scattering matrices from large eddy simulation. Application to a sudden area expansion of a duct. J. Sound Vib. 331(13), 3096-3113 (2012)

150. Tay-Wo-Chong, L., Bomberg, S., Ulhaq, A., Komarek, T., Polifke, W.: Comparative validation study on identification of premixed flame transfer function. J. Eng. Gas Turbines Power 134(6), 1-8 (2012)

151. Motheau, E., Nicoud, F., Poinsot, T.: Mixed acoustic-entropy combustion instabilities in gas turbines. J. Fluid Mech. 749, 542-576 (2014)

152. Giusti, A., Worth, N.A., Mastorakos, E., Dowling, A.P.: Experimental and numerical investigation into the propagation of entropy waves. AIAA J. 55(2), 446-458 (2017)

153. Morgans, A.S., Goh, C.S., Dahan, J.A.: The dissipation and shear dispersion of entropy waves in combustor thermoacoustics. J. Fluid Mech. 733, R2 (2013)

154. Xia, Y., Duran, I., Morgans, A.S., Han, X.: Dispersion of entropy perturbations transporting through an industrial gas turbine combustor. Flow Turbul. Combust. 100(2), 481-502 (2018)

155. Waugh, I., Illingworth, S., Juniper, M.: Matrix-free continuation of limit cycles for bifurcation analysis of large thermoacoustic systems. J. Comp. Phys. 240, 225-247 (2013) 
156. Kypraiou, A., Allison, P., Giusti, A., Mastorakos, E.: Response of flames with different degrees of premixedness to acoustic oscillations. Combust. Sci. Technol. pp. 1-16 (2018)

157. Schulz, O., Noiray, N.: Autoignition flame dynamics in sequential combustors. Combust. Flame 192, 86-100 (2018)

158. Bolla, M., Farrace, D., Wright, Y.M., Boulouchos, K., Mastorakos, E.: Influence of turbulencechemistry interaction for $n$-heptane spray combustion under diesel engine conditions with emphasis on soot formation and oxidation. Combust. Theory Model. 18(2), 330-360 (2014)

159. Sazhin, S.S.: Modelling of fuel droplet heating and evaporation: Recent results and unsolved problems. Fuel 196, 69-101 (2017)

160. Felden, A., Riber, E., Cuenot, B.: Impact of direct integration of Analytically Reduced Chemistry in LES of a sooting swirled non-premixed combustor. Combust. Flame 191, 270-286 (2018)

161. Koniavitis, P., Rigopoulos, S., Jones, W.: Reduction of a detailed chemical mechanism for a kerosene surrogate via RCCE-CSP. Combust. Flame 194, 85-106 (2018)

162. Prager, J., Najm, H.N., Valorani, M., Goussis, D.A.: Skeletal mechanism generation with CSP and validation for premixed n-heptane flames. Proc. Combust. Inst. 32(1), 509-517 (2009)

163. Lenin, M., Swaminathan, M., Kumaresan, G.: Performance and emission characteristics of a DI diesel engine with a nanofuel additive. Fuel 109, 362-365 (2013)

164. Mehta, R.N., Chakraborty, M., Parikh, P.A.: Nanofuels: combustion, engine performance and emissions. Fuel 120, 91-97 (2014)

Publisher's Note Springer Nature remains neutral with regard to jurisdictional claims in published maps and institutional affiliations.

\section{Affiliations}

\section{A. Giusti ${ }^{1,2} \cdot$ E. Mastorakos ${ }^{1}$}

\section{A. Giusti}

a.giusti@imperial.ac.uk

1 Department of Engineering, University of Cambridge, Trumpington Street, Cambridge, CB2 1PZ, UK

2 Department of Mechanical Engineering, Imperial College London, South Kensington Campus, London, SW7 2AZ, UK 